\title{
A Comparison of Digital Reading Behaviors Among Graduate Students in
}

\section{Taiwan and The USA}

\author{
Suyu Lin ${ }^{1, *}$, Chia-Hsiang Chen ${ }^{2}$, Hao-Ren $\mathrm{Ke}^{3}$ \\ ${ }^{1}$ Tamkang University, Taiwan \\ ${ }^{2,3}$ National Taiwan Normal University, Taiwan \\ ${ }^{1}$ slin20@csu.edu *; ${ }^{2} 80015003 \mathrm{e} @$ ntnu.edu.tw; ${ }^{3}$ clavenke@ntnu.edu.tw \\ * Corresponding author
}

(Received July 4, 2021 Revised August 11, 2021 Accepted August 31, 2021, Available online September 1, 2021)

\begin{abstract}
This is a comparative study on digital reading behaviors between students in Graduate Institute of Library and Information Studies (GLIS) in National Taiwan Normal University and School of Information Studies (SOIS) in University of Wisconsin-Milwaukee. By making a connection between their habits and various forms of capital that may shape their reading behaviors, this study adopts a qualitative approach to focus on the four key concepts of Bourdieu's practice theory: habitus, economic capital, cultural capital, and social capital to analyze the factors that influence digital-reading behaviors. The results indicate that the graduate students' digital reading behavior is influenced mostly by their family, school and library. Graduate students like to use electronic resources (online database and the Internet) to conduct academic research and still prefer print textbooks. When comes to digital reading, in GLIS, students with more than two digital reading devices tend to get free digital contents from various sources. However, in SOIS, students with more than one digital reading service tend to purchase digital contents from the Internet. Graduate students' reading behaviours might be influenced by their economic capital.
\end{abstract}

Keywords: Digital reading; User studies; Pierre Bourdieu;

\section{Introduction}

Over the last decades, the widespread use of digital resources has dramatically impacted reading behavior. Many studies found an increasing amount of time spending on reading electronic documents, indicating that a screen-based reading behavior is emerging. Digital reading has become a focus of numerous studies [28]. Aflred P. Solan Foundation [3] included reading behavior as one of the study areas of scholarly communication.

Meeker [16] showed that the number of Internet users to 35 million in 1995, accounting for 0.6 percentage of the global population, and the number rose to 2.8 billion by 2014, accounted for 39 percentage of the world's population. The world has become a text-saturated world thanks to the widespread use of Internet [4] [8].

The variety of available genres on the Internet has gradually changed the reading literacy; digital technology has also become an important accomplishment of the information society of citizens. The technology itself becomes an important contemporary research issue to explore the digital reading research [21] [22] [25]. Due to the development of new technologies and the reading behaviors associated with different technologies presented together, digital reading can now be defined as the use of computer or carry-on online reading activities. Display digital reading will go hand in hand with the ongoing development of the information society [7] [9].

In the information technology era, people rely on the use of computers, digital carrier and network; this new behavior forms cultural symbols, community networks, and even an information society. Moreover, the changes cause new cultural and economic value [13]. Aulia, Vianty \& Ihsan [20] on the impact of reading behavior of factors, including family economic, social, cultural and educational background, Kvasny and Keil [14] and Glove [11] and other 
scholars quoted the Bourdieu culture Reproduction theory (Cultural reproduction) [18], scholarly discussions on habitus, cultural capital, social capital and economic capital are based on the qualitative point of view in the era of knowledge economy, delineating how information and communication technology shapes social evolution, while it maintains continuing education and social order.

From an agricultural society to an industrial society and then developed into an information society, social background between the United States and Taiwan is similar [12]. This project is based on a comparative study of digital reading in GLIS and SOIS.

Based on the above background, root-based reading itself has embedded in the historical, social, technological and behavioral contexts [17]. This research begins by presenting Pierre Bourdieu's theory of practice [18]. Drawing upon his work to analyze the use of various reading sources, this study uses a qualitative approach to investigate how habitus, economic capital, cultural capital, and social capital shape students' digital reading behavior.

Table. 1. Bourdieu's Theoretical Concepts

\begin{tabular}{|l|l|}
\hline Theoretical concept & Related codes \\
\hline Habitus & Individual's lifestyle, family, class \\
\hline Economic capital & Money, assets, cash, costs, prices, investment \\
\hline Cultural capital & $\begin{array}{l}\text { Skills, knowledge, know-how, education, qualifications, } \\
\text { cultural artifacts, experiences }\end{array}$ \\
\hline Social capital & $\begin{array}{l}\text { Networks, meetings, friends, family, community, social } \\
\text { connections, professional }\end{array}$ \\
\hline
\end{tabular}

This theoretical framework enables us to consider not only how information technology, but also how different habits and capitals influence the reading behavior of LIS graduate students. This is a comparative study on digital reading behaviors between students in Graduate Institute of Library and Information Studies (GLIS) in National Taiwan Normal University and in School of Information Studies (SOIS) in University of Wisconsin--Milwaukee. By making a connection between their habits and various forms of capital that may shape their reading behaviors, this study adopts a qualitative approach to focus on the four key concepts of Bourdieu's practice theory: habitus, economic capital, cultural capital, and social capital to analyze the factors that influence the digital reading behaviors. The paper presents research findings that answer the following research questions:

- Which factors influence graduate students' reading habitus?

- How do graduate students spend money on electronic devices that access digital contents?

- What academic sources do graduate students use for academic activities?

- Which social networks do graduate students use to share and connect to others?

\section{Literature review}

Liu [25] pointed out that with the popularity of Internet applications and digital resources, the fast, convenient, audio-visual hyperlinks and other advantages have a huge impact on the reading behavior. Cull [4] that reading is shaping modern society and advancing core activities. What are the impacts of Information and Communication Technology exchange and dissemination of human knowledge of reading is an important research topic. This study is based on theoretical discussion of how cultural Reproduction is related to graduate students' reading behaviors. Discussed in the literature section, sequentially on the status and culture between Taiwan and the United States, we reconfigure the theory of digital reading behavior. 


\subsection{The Development of Digital Reading Behaviors in Taiwan and USA}

In 1971, Gutenberg eBook Project (Project Gutenberg) came out to lay the foundation for the United States the popularity of digital reading. Since 1990, Taiwan began to promote the use of personal computers, leading digital reading to sprout development. digital reading in the US and Taiwan was ahead of many other countries [15][24]. In the ICT's rapid development nowadays, digital media has become a core technology that students have to learn. The shift from paper to digital forms of course reading has its social implications. The digital environment will indirectly affect the reading behavior, but digital and paper reading is not mutually substituted.

Broadly speaking, a variety of digital processing of content can be called digital reading [10]. Digital reading is defined as: "conduct reading activities through digital media forms, such as the use of computers to read the file, blog or forum articles, etc., or using a mobile phone, PDA and other drawing and watch Novel". Lin [7] pointed out digital reading includes "e-books, e-journals, databases and network resources."

In 2012, Taiwan Digital Reading Behavior Survey [23] found that college education has a number of resources are the largest group of people and vehicles, are the main users of digital reading and related resources. It has shown that people with higher education, the higher the score the overall performance of digital, personal digital Institute educated more than 11 times the performance scores of primary education by. 2013 American Pew Internet Research [19] survey shows more than a third of Americans have the Tablet PC, is proportional to the ratio of the plate has a level of education, university education, $49 \%$ have a tablet, while only $21 \%$ of high school graduates own a tablet.

Catalano [2] argues that graduate students' information and complex behavior is more mature than that of college students, affecting their reading behavior. Liew, Foo \& Chennupati [6] conducted 83 graduate students surveys about the use of electronic journals. They found that more than 73 percent of students preferred to use electronic journals, because readers can be directed to other resources; the digital features are searchable readily available, and accessible. Friedlander's [1] study shows both faculty and graduate students use both printed and electronic resources in their academic environment.

Liu's [27] analysis of the United States San Jose State University about the status of the use of electronic journals includes four departments: Library and Information Science (Library and Information Science $/ \mathrm{n}=42$ ), Business Studies (Business $/ \mathrm{n}=33$ ), computer science (computer science $/ \mathrm{n}=35$ ) and social sciences (Social science $/ \mathrm{n}=23$ ). With a total of 133 respondents, the study found that students are heavy users of library electronic resources, while graduate students can expect access to electronic resources paper resources and academic environment.

\subsection{Cultural Reproduction Theory}

Cultural Reproduction concept was coined by Pierre Bourdieu in the early 1970s. This term refers to social class using a variety of economic and cultural resources to maintain their own generational status of phenomenon or process. Educational research applying Bourdieu's theory focuses on the role of the education system in the delivery of cultural capital; it also examines how education system remakes cultural capital allocation, rather than a fundamental change. Through the cultural capital of the intermediary, the education system is becoming mechanism of social re-making. Because the Internet generation forms a vast virtual community, a global trend of the information age emerges in this new information environment, social and cultural differences, leading to growing class of users. The formation of digital reading behavior and information involves an access gap; there are factors that affect reading behavior, including domestic economic, social, cultural and educational background, etc. [5] [13] [20].

Kvasny \& Keil [14] and Glove [11] and other scholars quoted the French thinker Pierre Bourdieu's [18] theory of cultural Reproduction, mainly consisting of four dimensions of habitat, cultural capital, social capital and economic capital (see Table 1), Bourdieu's theory was considered as a way of understanding of the social facts, examine differences between members of society access to information. There is an important gap between theory indemnity level. This study accordingly explores how information and communication technology shapes reading behavior. 


\section{Research Model}

Using case studies, one of the qualitative research methods, we explore personal experiences and behavior. To investigate their subjective world of ideas and knowledge, we focus on the feelings and behaviors of a "small sample" and "specific groups" within a natural context. In this case, we explore graduate digital reading behavior in terms of its meaning and perspective. In this study, we adopt "cultural reproduction" as the theoretical framework, explaining the habitus, cultural capital, social capital and economic capital of the four-oriented comparative analysis GLIS and SOIS Graduate digital reading behavior. This can become the a reference for libraries which provide and use educational resources. Sub-study course domain object, study implementation are analyzed in the following sequence.

\subsection{Cultural Reproduction Theory}

University of Wisconsin-Milwaukee (UWM) is the sister school of National Taiwan Normal University, and signed a memorandum of academic exchanges and cooperation, Since 2009, the GLIS and SOIS has established long-term cooperative learning relations, the two sides exchange visits each year since teachers or students, academic exchanges. The study took place in two countries and semi-structured interviews were conducted. Founded on the basis of cooperation, we can analyze the digital reading behaviors of two groups of graduate students.

\subsection{Description of Implantation Research}

This study is an exploratory research; an interview outline is drafted based on the literature review. We take perspectives of qualitative research, with a small sample study to in-depth interviews, supplemented by literature analysis, the study of Taiwan GLIS and the United States SOIS graduate student, respectively. We carried out the interviews in both Taiwan and the United States among respondents who agreed that their interview content to be transcribed. And then, we use the theoretical framework for analysis, as detailed in Table 2.

Table. 2. Illustrative of implementation research

\begin{tabular}{|l|l|l|l|}
\hline \multicolumn{2}{|l|}{} & GLIS & SOIS \\
\hline \multirow{2}{*}{ Sampling } & Convenience sampling & Convenience sampling \\
\hline \multirow{2}{*}{ Date } & January to March, 2015. & May to August, 2015. \\
\hline \multirow{5}{*}{ Time } & Female & 40 minutes in average & 12 \\
\cline { 2 - 5 } Number & Male & 9 & 6 \\
\cline { 2 - 5 } & PhD Student & 6 & 11 \\
\cline { 2 - 5 } & Master Student & 3 & 7 \\
\hline \multirow{5}{*}{ Nationality } & Taiwan & 12 & 0 \\
\cline { 2 - 5 } & China & 0 & 6 \\
\cline { 2 - 5 } & South Korea & 0 & 4 \\
\cline { 2 - 5 } & American & 0 & 8 \\
\hline
\end{tabular}




\subsection{Data Analysis}

After the interviews were transcribed, we assigned the complete transcripts with the item numbers (for example, GLIS-1、GLIS-2、GLIS-3; SOIS-1、SOIS-2、SOIS-3), Fitting in the theme and content analysis of interviews in Table 3, we drew our conclusions and developed the discussion.

Table. 3. Analysis examples

\begin{tabular}{|c|c|c|}
\hline Order & Quotations & Analysis dimension \\
\hline GLIS-2 & $\begin{array}{l}\text { "Because universities offer } \\
\text { computer classes, we need to use } \\
\text { the computer; my mother bought } \\
\text { one at home for every family } \\
\text { members to do homework. } \\
\text { Therefore, we took a digital reading } \\
\text { habit." (GLIS-2:3-4) }\end{array}$ & Habits \\
\hline GLIS-14 & $\begin{array}{l}\text { "I never buy any electronic journals } \\
\text { or books online. I use the resources } \\
\text { from Normal library, or obtain } \\
\text { digital resources within the network } \\
\text { of my fellow students, etc.. By } \\
\text { doing so, I do not need to spend my } \\
\text { own money on it." (GLIS-14: } \\
\text { 30-32) }\end{array}$ & Economic capital; cultural capital. \\
\hline SOIS-5 & $\begin{array}{l}\text { "I only use Facebook nowadays } \\
\text { because my relatives and friends are } \\
\text { doing so. Reading information in a } \\
\text { digital form has become an } \\
\text { important part of my life. Annotates } \\
\text { and highlight some useful digital } \\
\text { content. I also make photocopies of } \\
\text { them. These actions can facilitate } \\
\text { my organization of knowledge } \\
\text { obtained. When I went back to } \\
\text { South Korea, I observed many } \\
\text { people still read printed books. It } \\
\text { seems that the popularity of digital } \\
\text { reading in South Korea is lower } \\
\text { than that in the United States. } \\
\text { Because I study in the United } \\
\text { States, I can observe that my kids } \\
\text { and their generation is immersed in } \\
\text { using digital devices. They read } \\
\text { information from the digital reader } \\
\text { and they can digest the content } \\
\text { naturally. I think libraries and } \\
\text { bookstores will gradually phase out, } \\
\text { or even disappear, indicating the } \\
\text { future of the digital world. " }\end{array}$ & Social capital \\
\hline SOIS-6 & "We get due days to return any & Economic capital; cultural capital \\
\hline
\end{tabular}




\begin{tabular}{|l|l|}
\hline & $\begin{array}{l}\text { books to the libraries. We buy our } \\
\text { own e-books from Amazon and } \\
\text { Google bookstore. The price is } \\
\text { reasonable and my experience is } \\
\text { fairly satisfactory. I also often use } \\
\text { the library interlibrary loan service, } \\
\text { which is free and efficient. I just } \\
\text { prefer electronic archives than } \\
\text { printed versions. " (SOIS-6:28-31) }\end{array}$ \\
\hline
\end{tabular}

\section{Implementation and Discussion}

Since the act of reading has a social nature, this study uses four facets of Cultural Reproduction Theory to explore graduate from customary between practice and the capital of the shaping of reading behavior. The following research findings illustrate Taiwan GLIS and US SOIS graduate student reading behavior and the use of digital resources in the current situation.

\subsection{Taiwan GLIS}

Effects of Graduate digital reading behavior of habitus are affected by several factors: personal thirst for knowledge, peer pressure, family, schools, libraries and community expectations, the degree of the premise, habits of reading academic journals, the need for using textbook as a habit, the frequent use of the Internet to download information or print out articles, and leisure reading the printed version of books.

The use of economic capital: respondents owned more than two or more digital reading devices, such as notebook computers, smart phones, tablets and desktop computers. They needed access to digital content, and tended to use the academic resources that libraries offer free usage. These respondents had a fixed budget for the books for leisure reading.

The respondents accumulated cultural capital, known as their new knowledge, by accessing information through digital resources in Taiwan Normal University Library. Respondents never made use of the library e-book reader due to privacy considerations. Digital resources and Paper Resources cannot replace each other.

Social capital network: the respondents share digital media content, including Email, Facebook, Line, Dropbox and Evernote. Because most of the family, friends and colleagues communicated via Facebook and Line Messenger, these two media became the most commonly used community website.

\subsection{USA SOIS}

Factors affecting graduate digital reading behavior (their habitus) include family, friends, school, teacher, library, time, digital information obtained conveniently and the functions of digital carrier., The main purpose of conducting academic research, accessing professional information, developing personal interests and leisure entertainment are also influential; the respondents like to use digital resources for academic research; however, for reading resources, textbooks and leisure reading, they still prefer paper books.

The use of economic capital: eight respondents have four kinds of digital readers; eight have three kinds of digital readers; one has two kinds of digital reader and one has a digital reader. notebook computers, smartphones and desktop computers were tied for the most commonly used digital reading vehicle, followed by the Tablet PC; for those who need digital content access, four are accustomed to the use of university libraries or public libraries academic resources to get free the resources for the premise, the other 14 not only use library resources, but also choose to buy books full payment or other digital content.

Education and cultural capital: respondents who accumulated knowledge have access to the account password information power; the students use digital resources to enter UW-Milwaukee e-library, and also Google scholar and Milwaukee Public Library; two respondents borrowed Library eBook reader, 14 respondents have a device which 
does not require the use of the service; two respondents could not borrow the e-book reader because it was too popular and they had overdue items. These two factors affected their behavior of taking advantage of this service.

Social capital: interwoven network helps respondents to share digital reading contents of ways, namely: Email, Facebook, Dropbox, and face-to-face interaction. The respondents think Facebook is not just a social media but it is also a content-rich site; the information there is rich and diverse; respondents can easily share information. With relatives and friends. Facebook is the most popular social networking site.

\subsection{A Comparison of Digital Reading Behaviors}

Table 4 offers a comparison of digital reading behaviours among graduate students in Taiwan and the USA.

Table. 4. BCRs of different JPEG QF attacks on image LENA

\begin{tabular}{|l|l|l|}
\hline Habitus & GLIS & SOIS \\
\hline Economic capital & $\begin{array}{l}\text { Personal thirst for knowledge, peer } \\
\text { pressure, family, schools, libraries } \\
\text { and community expectations, } \\
\text { textbook chapter good read on } \\
\text { paper. }\end{array}$ & $\begin{array}{l}\text { Family, friends, school, teacher, } \\
\text { library, time, digital information } \\
\text { obtained conveniently and digital } \\
\text { carrier charm, good reading } \\
\text { textbook chapter on paper. }\end{array}$ \\
\hline $\begin{array}{l}\text { All have more than two digits of } \\
\text { reading vehicle, tend to use the free } \\
\text { academic resources. }\end{array}$ & $\begin{array}{l}\text { There are eight respondents who } \\
\text { have four kinds of digital readers, } \\
\text { eight have three kinds of digital } \\
\text { readers, one has two kinds of digital } \\
\text { reader and one has a kind of digital } \\
\text { readers, most prefer to use their own } \\
\text { resources to pay. }\end{array}$ \\
\hline Cultural capital & $\begin{array}{l}\text { Academic Resources made a major } \\
\text { conduit for Taiwan Normal } \\
\text { University Library, respondents } \\
\text { were never made use of the library } \\
\text { e-book reader this service. }\end{array}$ & $\begin{array}{l}\text { The main pipeline for UWM digital } \\
\text { library resources, the respondents, } \\
\text { only two made use of the library } \\
\text { e-book reader to borrow this } \\
\text { service. }\end{array}$ \\
\hline Social capital & $\begin{array}{l}\text { Share digital content by Email, } \\
\text { Facebook, Line, Dropbox and } \\
\text { Evernote, social networking site } \\
\text { Facebook and is most commonly } \\
\text { used Line. }\end{array}$ & $\begin{array}{l}\text { Share digital content by Email, } \\
\text { face, is the most commonly used } \\
\text { social networking site Facebook }\end{array}$ \\
\hline
\end{tabular}

\section{Conclusions and Suggestions}

Reading history is shaped by a number of changes due to the development of new technology, particularly Internet features which make far-reaching effects. Reading behavior along different technology and culture presents different faces, and also generates the gap of information accessibility.

The present study shows that both in Taiwan or the United States, family and education institutions are developing reading habit as an important field; while people prefer to read textbook chapter on paper, those with better economic capitals can reach the digital content; they can be free of being dependent. Cultural capital is an important foundation of knowledge and academic resources available; with the school account number and password to access a resource threshold, attending university library website resources has become a good source for graduate students doing research. For libraries offer digital lending reader service, they can consider their future for the perspective of user privacy and late return penalties way to provide a better use; social capital Instruction Contact pipeline network and 
S. Lin et al / IJIIS vol. 4, no. 2, September 2021, pp 130-137

share digital resources, in addition to the United States graduate students through electronic transfer, face to face contact is still the pipeline, Facebook is popular social networking sites, because graduates in the United States does not use Line.

This study is based on the theory of cultural remaking, since people with capital result in different reading behaviors. By conducting a qualitative and comparative study of Taiwanese GLIS and the United States SOIS graduates, we recommend that future studies can be a quantitative one. Interdisciplinary research can help future exploration of how different groups have their own kinds of digital reading behavior.

\section{References}

[1] A. Friedlander, Dimensions and use of the scholarly information environment. Council of Library and Information Resources, 2002.

[2] A. J. Catalano, Patterns of graduate students' information seeking behaviour: A meta-synthesis of the literature. Journal of Documentation, 69(2), 243-274, 2013.

[3] Alfred P. Sloan Foundation, Trust and authority in scholarly communications in the light of the digital transition: Final report. 2013.

[4] B. W. Cull, Reading revolutions: Online digital text and implications for reading in academe. First Monday, 2011.

[5] C. H. Chang, A research on the relationship between family literacy and reading behavior of 5th and 6th Graders: The case in Luzhou City of Taipei County. 2009.

[6] C. L. Liew, S. Foo, and K. R. Chennupati, A study of graduate student end-users: Use and perception of electronic journals. Online Information Review, 24(4), 302-315, 2000.

[7] D. Durant and T. Horava, The future of reading and academic libraries. Libraries and the Academy, 15(1), 5-27, 2015.

[8] E. Bleeker, On reading in the digital age: Establishing the paradigms in a hyperbolical discussion. Lezen, 2010. Available at: http://www.stichtinglezen.be/uploads/scriptieprijs/bleeker_red.pdf

[9] J. L. Glove, Capital usage in adverse situations: Applying Bourdieu's theory of capital to family farm business. Journal of Family and Economic Issues, 31(4), 485-497, 2010.

[10]L. Baker, D. Scher and K. Mackler, Home and family influences on motivations for reading. Educational Psychologist, 32(2), 69-82, 1997.

[11] L. Kvasny and M. Keil, The challenges of redressing the digital divide: A tale of two US cities. Information Systems Journal, 16: 23-53, 2006.

[12] M. Meeker, Internet trends 2015: Code conference. KPCB, May 2015.

[13]N. Doidge, The brain that changes itself: Stories of personal triumph from the frontiers of brain science, Viking, 2007.

[14]L. C. Larson, "Digital Readers: The Next Chapter in E-Book Reading and Response," Read. Teach., vol. 64, no. 1, pp. 15-22, 2010, doi: 10.1598/rt.64.1.2.

[15] Š. Sonja, The Fourth European Conference on Information Literacy ( ECIL ): Abstracts The Fourth European Conference on Information Literacy ( ECIL ), no. October. 2016.

[16]E. Farhana, T. Rutherford, and C. F. Lynch, "Investigating Relations between Self-Regulated Reading Behaviors and Science Question Difficulty," Proc. 13th Int. Conf. Educ. Data Mining, EDM 2020, no. Edm, pp. 395-402, 2020.

[17]L. Flores, "Digital Textuality and its Behaviors," J. Comp. Lit. Aesthet., vol. 36, no. 1/2, p. 97, 2013.

[18] S. Sugiyanto, "Predict high school students' final grades using basic machine learning," J. Appl. Data Sci., vol. 2, no. 1, pp. 26-39, 2021, doi: 10.47738/jads.v2i1.19. 
S. Lin et al / IJIIS vol. 4, no. 2, September 2021, pp 130-137

[19] A. S. M. Al-rawahnaa, A. Yahya, and B. Al, "Data mining for Education Sector, a proposed concept," J. Appl. Data Sci., vol. 1, no. 1, pp. 1-10, 2020.

[20] Y. M. Huang, T. H. Liang, and C. H. Chiu, "Gender differences in the reading of e-books: Investigating children's attitudes, reading behaviors and outcomes," Educ. Technol. Soc., vol. 16, no. 4, pp. 97-110, 2013.

[21]Y. Xu, J. C. Yau, and S. M. Reich, "The Added Challenge of Digital Reading," pp. 432-438, 2019, doi: $10.1145 / 3311927.3323121$.

[22] P. Bourdieu, and J. C. Passeron, Reproduction in education, society, and culture Sage Publications, 1990. [19]

[23]Pew Research Center Survey, 2013.

[24]R. Aulia, M. Vianty, and D. Ihsan, Students' reading motivation, reading achievement and parents' economic status. Journal of English Literacy Education, 1(2), 1-12, 2014.

[25] S. A. Saaid and Z. A. Wahab (2014). The impact of digital-based materials on undergraduates' reading habit. International Journal of Social Science and Humanity, 4(3), 249-253, 2014.

[26]Z. Liu, Reading behavior in the digital environment: Changes in reading behavior over the past ten years. Journal of Documentation, 61(6), 700-712, 2005.

[27]Z. Liu, Digital reading: An overview. Chinese Journal of Library and Information Science, 5(1), 85-94, 2012.

[28]Z. Liu, Print vs. electronic resources: A study of user perceptions, preferences, and use. Information Processing \& Management, 42(2): 583-592, 2006.

[29]Z. Liu, Trends in transforming scholarly communication and their implications. Information Processing and Management, 39(6), 889-898, 2003. 